\title{
Prevalence of Superior Semicircular Canal Dehiscence in Coronal Images of Temporal Bone Computed Tomography and Its Diagnostic Value in Korean Population
}

\author{
Eun Sub Lee, Yong Tae Cho, Yong-Hwi An, and Hyun Joon Shim \\ Department of Otorhinolaryngology-Head and Neck Surgery, Eulji University School of Medicine, Eulji Medical Center, Seoul, Korea
}

\author{
한국인에서 측두골 전산화단층촬영 관상면 영상에서 상반고리관 피열의 발생률과 그 진단적 가치 \\ 이은섭 · 조용태 · 안용휘 · 심현준 \\ 을지대학교 의과대학 을지병원 이비인후과학교실
}

Received August 1, 2017

Revised September 22, 2017

Accepted October 16, 2017

Address for correspondence

Hyun Joon Shim, MD, PhD

Department of Otorhinolaryngology-

Head and Neck Surgery,

Eulji University School of Medicine,

Eulji Medical Center,

68 Hangeulbiseok-ro, Nowon-gu,

Seoul 01830, Korea

Tel $+82-2-970-8276$

Fax $+82-2-970-8275$

E-maileardoc11@eulji.ac.kr
Background and Objectives This study aimed to analyze the prevalence of superior semicircular canal dehiscence (SSCD) in the coronal images of high-resolution temporal bone computed tomography (TBCT) and to evaluate the diagnostic accuracy of coronal images for SSCD syndrome.

Subjects and Method We retrospectively reviewed high-resolution TBCT scans of 217 patients (434 ears) with SSCD due to various causes. The dehiscence ratio (slices showing dehiscence/total slices showing the superior semicircular canal) in the coronal images of TBCT was calculated, and the optimal cutoff value for the diagnosis of SSCD syndrome was determined using the receiver operating characteristics (ROC) curve.

Results Of the 434 ears, $64(14.7 \%)$ presented SSCD in more than one slice of the coronal images of TBCT, but only three patients $(0.7 \%)$ were confirmed with SSCD syndrome. Based on the ROC curve analysis for the dehiscence ratio of 64 ears, the optimal cutoff value for the diagnosis of SSCD syndrome was 0.67 with $100 \%$ sensitivity and $90.2 \%$ specificity.

Conclusion The majority of cases diagnosed with SSCD syndrome using the coronal images of TBCT were asymptomatic or false-positive. The dehiscence ratio in the coronal images of TBCT combined with a typical symptom can be a highly sensitive and specific diagnostic tool for SSCD syndrome. Korean J Otorhinolaryngol-Head Neck Surg 2018;61(9):453-8

Key Words Computed tomography $\cdot$ ROC curve $\cdot$ Semicircular canals.
서 론

상반고리관 피열증후군(superior semicircular canal dehiscence syndrome)은 상반고리관에 결손이 있는 환자에서 소리자극이나 귀의 압력 변화에 의해 어지럼증을 유발하는

This is an Open Access article distributed under the terms of the Creative Commons Attribution Non-Commercial License (https://creativecommons.org/licenses/by-nc/4.0) which permits unrestricted non-commercial use, distribution, and reproduction in any medium, provided the original work is properly cited.
질환으로 상반고리관의 결손이 제 3 의 창으로 작용하여 비정 상적인 림프액의 흐름이 발생하여 증상이 유발되는 것으로 추정된다. ${ }^{1)}$ 1998년 Minor 등에 의해 최초로 보고된 이후 그 증상 및 기전에 대한 연구가 활발히 이루어져 왔으며, 국내 에서는 2007년 첫 증례가 보고되었다. ${ }^{3)}$ 소리자극에 의해 병적 인 어지럼이 유발되는 Tullio 현상과 압력자극에 의해 어지럼 이 발생하는 Hennebert 징후가 이 질환의 대표적인 증상으 로 알려져 있으며, 측두골 전산화단층촬영(temporal bone 
computed tomography, TBCT)을 통해 상반고리관의 피열 을 확진할 수 있다. $\mathrm{TBCT}$ 는 상반고리관 피열증후군의 진단 에 가장 정확한 방법으로 알려져 있으낟) 상반고리관 피열이 없는 정상인의 $\mathrm{TBCT}$ 에서도 피열이 의심되는 위양성 소견이 관찰될 수 있으므로 $\mathrm{TBCT}$ 결과와 증상, 이학적 소견을 종 합적으로 고려하여 진단하여야 한다. 실제로 Williamson 등하 은 다양한 이과적 증상으로 $1 \mathrm{~mm}$ 두께의 관상면으로 촬영 된 39개의 TBCT를 후향적으로 분석한 결과 9\%에서 상반고 리관 피열을 확인할 수 있었지만 연관된 증상이 있는 경우는 거의 드물었다고 보고하였다. 임상에서 상반고리관 피열증후 군을 의심하지 않고 다른 질환을 진단하기 위하여 촬영한 $\mathrm{TBCT}$ 의 관상면 영상에서 우연히 상반고리관 피열이 확인되 는 경우가 있다. 이러한 경우는 증상을 일으키지 않는 잠복 된 상반고리관 피열증후군이거나 영상학적 진단의 한계로 과다하게 진단된 위양성 예가 될 것이다. 한국인의 TBCT 영 상 소견을 바탕으로 시행한 기존 연구에서 상반고리관 피열 증후군과 관련된 임상증상은 동반되지 않은 정상귀에서 상 반고리관 피열이 발견되는 경우가 0.3 1.2\%로 보고된 바 있 다. ${ }^{7}$ 저자들은 후향적으로 일정 기간 다양한 이유로 촬영된 $\mathrm{TBCT}$ 의 관상면 영상에서 상반고리관 피열이 확인되는 빈도 를 확인하여 증상 없이 $\mathrm{CT}$ 에서만 피열이 확인되는 빈도와 그중 임상증상을 고려하여 실제 상반고리관 피열증후군으로 진단되는 양성 예측도를 확인해 보고자 하였다.

또한 임상에서 상반고리관 피열증후군이 의심되는 증상이 나 이학적 검사 소견이 있는 경우 $\mathrm{TBCT}$ 의 관상면 영상과 더 불어 상반고리관에 평행한 재구성 영상을 획득하여 확진을 하게 되지만 장비 또는 숙련된 인력의 부족으로 재구성 영상 이 만족스럽게 구현되지 않을 경우가 있으므로 관상면 영상 에서 피열이 나타나는 슬라이스의 개수를 기반으로 상반고리 관 피열증후군의 진단을 얼마나 정확히 할 수 있는지 분석하 여 보고자 하였다.

\section{대상 및 방법}

2016년 1월부터 2017년 3월까지 본원에서 다양한 이유로 $\mathrm{TBCT}$ 를 시행한 성인 환자 217명(434귀)을 대상으로 하여 관 상면 영상과 의무기록을 검토하였다. 217명 중 183 명은 만성 중이염 등 감염질환을 진단하기 위해서 $\mathrm{TBCT}$ 를 시행하였고, 12 명은 상반고리관 피열증후군 여부를 확인하기 위해, 11 명은 청력저하의 원인을 감별하기 위해, 6 명은 박동성 이명의 감별 진단을 위해, 그리고 나머지 4명은 기타 이유였다. 대상군의 연 령은 평균 55.5세(19 90세)였으며 남자 83명, 여자 134명이었다.

TBCT는 GE Healthcare LightSpeed Ultra 16(GE Health- care, Little Chalfont, UK)을 이용하여, 축상면에 대하여 0.625 mm의 두께로 $(120 \mathrm{kVp}, 220 \mathrm{mAs}$, field of view 180×180 mm) 촬영되었고, GE Advantage workstation 4.5 Software(GE Healthcare)를 이용하여 $0.625 \mathrm{~mm}$ 의 두께로 관상면 영상이 재구성되었다. 217 건의 대상 $\mathrm{TBCT}$ 중 임상증상에서 상반고 리관 피열증후군의 특징적인 증상을 보이는 환자 12 명에 대 해서는 상반고리관에 평행한 재구성 영상을 얻었고, 관상면 영상과 상반고리관 재구성 영상에서 피열이 확인되는 경우 상반고리관 피열증후군으로 확진하였다.

환자들의 TBCT의 관상면 영상에서 상반고리관 피열 여부 를 확인하였다(Fig. 1). 한 사람의 이비인후과 의사가 TBCT의 이미지를 PACS(Petavision)상에서 window level $350 \mathrm{HU}$, window width 3000 HU로 512×512 pixel image를 430\% 확대하여 관상면 영상에서 상반고리관 피열의 존재 여부를 확인하였다. 상반고리관 피열이 확인되면 공통각이 보이는 관상면 영상은 제외하고 상반고리관이 보이는 슬라이스 전 체 수와 그중 피열이 보이는 슬라이스 수를 세어 상반고리관 에서 피열 면이 차지하는 비율을 구하였다(Fig. 1).

상반고리관의 피열 비율과 나이 및 성별의 상관관계를 분석 하기 위해 SPSS 23.0(IBM Corp., Armonk, NY, USA)을 이용 하여 Pearson 상관분석 및 독립표본 $\mathrm{T}$ 검정을 시행하였다. $\mathrm{TBCT}$ 에서 보이는 상반고리관 피열 비율로 상반고리관 피열 증후군을 진단할 때 가장 적절한 절단값(cutoff value)을 도출 하기 위하여, 민감도와 특이도를 각각의 축으로 그래프를 그 리는 receiver operating characteristics(ROC) curve를 시행 하였고, 진단방법의 정확도를 측정하기 위해 ROC curve 아래 의 면적을 정량화하는 area under the ROC curve(AUC)를 구 하였다. ROC curve는 MedCalc 17.6(MedCalc Software bvba, Ostend, Belgium)을 사용하여 시행하였다. 통계의 유의성은 유의확률 0.05 미만을 기준으로 하였다. 본 연구는 을지대학 교 을지병원의 임상윤리위원회 심의를 승인받았다(IRB No. EMCS 2017-08-002).

\section{결 과}

434귀의 TBCT를 후향적으로 분석한 결과 64귀(14.7\%)에 서 관상 영상의 한 슬라이스 이상에서 상반고리관 피열이 관 찰되었고 그중 상반고리관 피열증후군으로 확진된 경우가 3 귀(3/434, 0.7\%)로 확인되었다.

환자의 임상적 증상을 고려하지 않고 $\mathrm{TBCT}$ 의 관상면 영상 만을 기준으로 한 슬라이스 이상의 피열 소견을 보인 환자를 상반고리관 피열증후군을 진단하는 경우 그 민감도 $100 \%$, 특 이도 $85.8 \%$ (위양성률 $14.2 \%$ ), 양성 예측도 $4.7 \%$, 음성 예측도 
Table 1. Diagnostic accuracy of the coronal image of temporal bone CT for SSCDS

\begin{tabular}{lcc}
\hline \multicolumn{1}{c}{ Total ears $(\mathrm{n}=434)$} & SSCDS ears & Non-SSCDS ears \\
\hline Predicted SSCDS & 3 & 61 \\
Predicted non-SSCDS & 0 & 370 \\
Sensitivity (\%) & 100 & \\
Specificity (\%) & 85.8 & \\
Positive predictive value (\%) & 4.7 & \\
Negative predictive value (\%) & 100 & \\
\hline
\end{tabular}

SSCDS: superior semicircular canal dehiscence syndrome
$100 \%$ 로 나타났다(Table 1), 관상면 영상에서 피열이 확인된 64귀 중 동일한 사람의 양측 귀에서 모두 피열이 관찰된 경우 는 26귀(13명)였다. 피열이 확인된 64귀의 관상면 영상에서 상반고리관은 5 9개(평균 $6.66 \pm 0.89$ 개)의 슬라이스에서 보

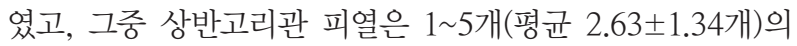
슬라이스에서 확인되어 [피열 확인 슬라이스/상반고리관 확 인 슬라이스] 비율은 0.11 0.83(평균 $0.40 \pm 0.21$ )으로 분포되 어 있었다(Fig. 2). 상반고리관 피열증후군으로 확진된 3귀의
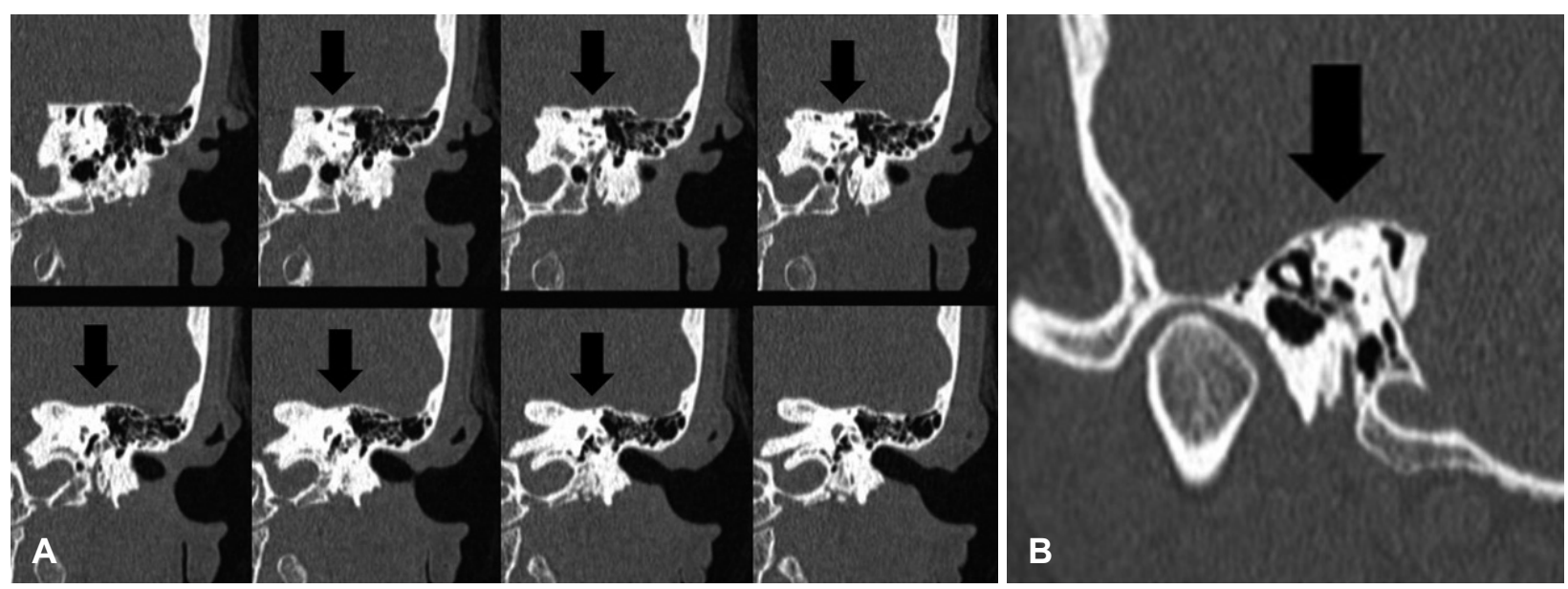

Fig. 1. Coronal image $(A)$ and oblique reformatted image in the superior semicircular canal $(B)$ of temporal bone CT. Arrows indicate dehiscences of left superior semicircular canal in series of coronal image.

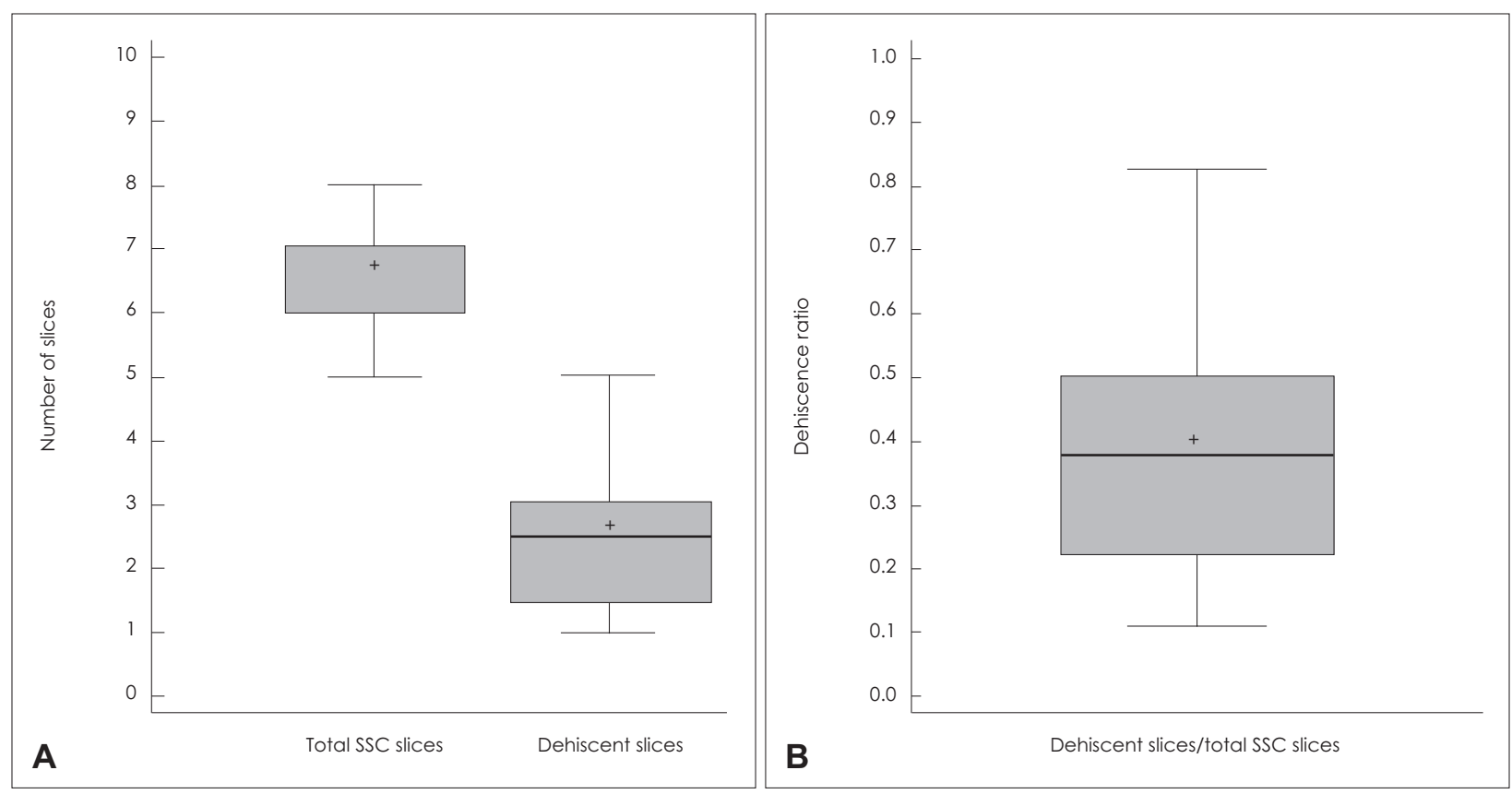

Fig. 2. The Box and Whisker plot for multiple slices showing SSCD of the superior semicircular canal (A). Among 64 ears with SSCD, numbers of temporal bone computed tomography slices showing the superior semicircular canal and the dehiscence of the superior


ratio (slices showing dehiscence/total slices showing superior semicircular canal) (B). The dehiscence ratios of the superior semicircular canal were $0.11-0.83$ (mean, $0.40 \pm 0.21$ ). Each box indicates the 25th-75th percentile range, and Whiskers indicate the minimum and maximum values. The vertical bars indicate the median, and + indicates mean. SSC: superior semicircular canal, SSCD: superior semicircular canal dehiscence. 
경우 [피열 확인 슬라이스/상반고리관 확인 슬라이스] 비율 은 각각 5/6(0.83), 5/7(0.71), 5/7(0.71)로 나타났다. TBCT 관 상면 영상에서 보이는 [피열 확인 슬라이스/상반고리관 확인 슬라이스] 비율로 상반고리관 피열증후군을 진단할 때 가장 적절한 절단값(cutoff value)은 ROC curve에서 0.67 로 나타 났고, 그 민감도는 $100 \%$, 특이도는 $90.2 \%$ 였으며, $\mathrm{AUC}$ 값은 0.95 로 통계적으로 유용한 검사방법으로 나타났다 $(p<0.0001)$ (Fig. 3). 절단값을 초과한 대상 수는 9귀(9/434, 2.1\%)였고 그 중 3귀(3/434, 0.7\%)는 상반고리관 피열증후군으로 확진되었 고 6귀 $(9 / 434,1.4 \%)$ 는 피열증후군의 증상이 없었던 경우였다.

217명의 전체 대상 환자 중 상반고리관 피열증후군을 시사 하는 증상을 보이는 경우가 12 명(12/217, 5.5\%) 있었고 12명 모두 상반고리관에 평행하게 재구성한 영상까지 획득하였는 데 그중 상반고리관 피열증후군으로 확진된 경우는 3명 (3/217, 1.4\%)이었다. 상반고리관 피열증후군 의심증상을 보 이는 환자 12 명의 순음청력검사에서 $10 \mathrm{~dB}$ 이상의 기도-골도

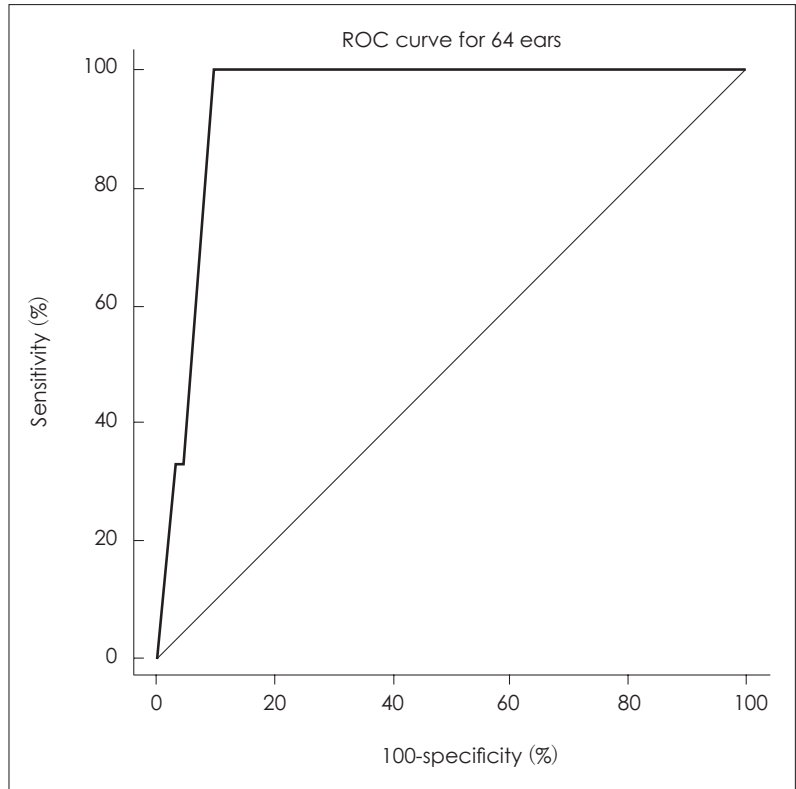

Fig. 3. The ROC curve for the dehiscence ratio of superior semicircular canal in coronal view of temporal bone CT. Area under curve was 0.95 and an optimal cutoff value was 0.67 with $100 \%$ sensitivity and $90.2 \%$ specificity. ROC: receiver operating characteristics.
차이를 보이는 전음성 난청 소견은 관찰되지 않았다. 상반고 리관 피열증후군으로 확진된 3명의 환자들에서는 전정유발 근전위 검사도 시행하였으나 정상측에 비해 $20 \mathrm{~dB}$ 이상의 낮 은 역치를 보이는 경우는 없었다. 상반고리관 피열증후군 관 련 증상이 있었던 12명의 환자에서 각 증상별 민감도, 특이도, 양성 예측도, 음성 예측도를 Table 2에 표시하였다.

$\mathrm{TBCT}$ 관상면 영상에서 확인되는 [피열 확인 슬라이스/상 반고리관 확인 슬라이스] 비율과 나이의 상관관계를 Pearson 상관분석을 통해 검증한 결과 통계적으로 유의미한 상관관 계는 보이지 않았다(r=-0.23, $p=0.07$ (Fig. 4). 상반고리관의 피열 비율과 성별의 상관관계를 독립표본 $\mathrm{T}$ 검정으로 확인하 였으나 유의미한 상관관계는 보이지 않았다 $(p=0.22)$.

\section{고 찰}

$\mathrm{TBCT}$ 는 가장 정확한 상반고리관 피열증후군의 진단법으 로 상반고리관과 평행한 영상 재구성을 포함하면 그 민감도 $100 \%$, 특이도 $96 \%$, 양성 예측도 93\%, 음성 예측도 $100 \%$ 로 가장 정확한 진단방법으로 알려져 있다.5) 그러나 상반고리관의

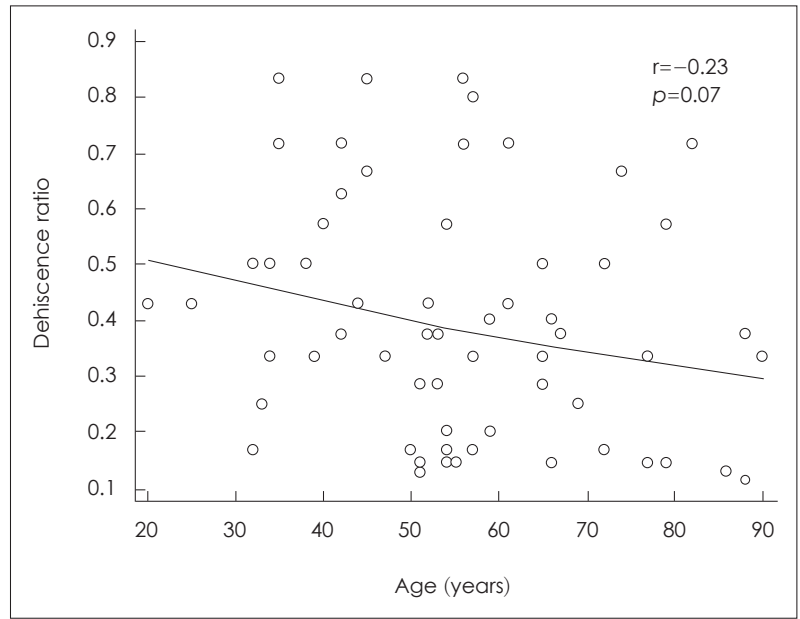

Fig. 4. Pearson's correlation test between age and superior semicircular canal dehiscence ratio. No significant correlations was found between dehiscence ratio of superior semicircular canal in coronal view of temporal bone CT and patient's age $(r=-0.23, p=0.07)$.

Table 2. Diagnostic values of symptoms in patients suspicious of superior semicircular canal dehiscence syndrome

\begin{tabular}{lcccc}
\hline \multicolumn{1}{c}{ Symptoms in patients } & Sensitivity & Specificity & PPV & NPV \\
\hline Tullio phenomenon, \% & $(3 / 3) 100$ & $(5 / 9) 55.6$ & $(4 / 7) 42.9$ & $(5 / 5) 100$ \\
Autophonia, \% & $(3 / 3) 100$ & $(7 / 9) 77.8$ & $(3 / 5) 60.0$ & $(7 / 7) 100$ \\
Hyperacusis & $(3 / 3) 100$ & $(5 / 9) 55.6$ & $(3 / 7) 42.9$ & $(4 / 4) 100$ \\
Pulsatile tinnitus & $(1 / 3) 33.3$ & $(7 / 9) 77.8$ & $(1 / 3) 33.3$ & $(7 / 9) 77.8$ \\
Fistula test & $(2 / 3) 66.7$ & $(8 / 9) 88.9$ & $(2 / 3) 66.7$ & $(8 / 9) 88.9$ \\
Tullio+autophonia+hyperacusis & $(3 / 3) 100$ & $(9 / 9) 100$ & $(3 / 3) 100$ & $(9 / 9) 100$ \\
\hline
\end{tabular}

PPV: positive predictive value, NPV: negative predictive value 
피열은 상반고리관 피열증후군과 관련된 증상이 없는 경우에 도 발견되므로 특징적 증상과 $\mathrm{TBCT}$ 소견이 일치하는 경우 에만 해당 증후군으로 진단하게 된다. 본 연구에서 다양한 이 유로 $\mathrm{TBCT}$ 를 촬영한 대상자 가운데 관상면 영상에서 상반 고리관 피열이 확인된 경우는 64귀(14.7\%)였으나 증상과 상반 고리관과 평행한 재구성 영상을 통하여 상반고리관 피열증 후군이 확인된 귀는 3 귀(0.7\%)로 $14.2 \%$ 의 위양성률을 보였 다. 본 연구에서 $\mathrm{TBCT}$ 관상면 영상에서 확인된 상반고리관 피열의 빈도는 $14.7 \%$ 로 $\mathrm{TBCT}$ 를 이용하여 연구한 기존 문헌 에서 보고한 9 12\%의 빈도와 큰 차이가 없었다. ${ }^{6}$ 그러나 부 검된 측두골 견본을 이용한 해부학적 연구에 있어 일반인의 $1.3 \%$ 에서 해부학적 소견상 골 피열이 명백하거나 매우 얇은 $(\leq 0.1 \mathrm{~mm})$ 소견이 관찰된다고 보고하여 $\mathrm{TBCT}$ 관상면 영상 에서 확인되는 상반고리관 피열의 빈도와 큰 차이를 보였다. ${ }^{8)}$ 그 이유는 첫째, $\mathrm{TBCT}$ 의 영상학적 한계점을 들 수 있다. 상 반고리관의 축이 관상면과 45도의 각도를 이루고 있다는 점 과 상반고리관 상부를 덮고 있는 $0.6 \mathrm{~mm}$ 두께의 중두개와가 ${ }^{9)}$ $0.625 \mathrm{~mm}$ 간격으로 촬영된다는 점을 고려하면 그 한계점을 이해할 수 있다. 둘째, 본 연구를 포함한 영상학적 연구는 해 부학적 연구와 달리 만성중이염을 포함한 이과적 질환을 의 심하여 촬영한 $\mathrm{TBCT}$ 를 대상으로 하였으며, 만성중이염이 상반고리관 피열증후군의 위험인자로 작용하여 피열의 발생 률이 더 높게 나타났을 가능성을 배제할 수 없다. 실제로 만성 중이염이 상반고리관 피열의 위험인자로 작용할 수 있음을 보고한 연구가 있다. ${ }^{7)}$ 그렇지만 관상면 영상에서 상반고리관 피열은 과다진단되는 경향이 있는 것은 분명한 것으로 보이 고, 그 안에는 영상학적 진단의 한계로 인한 위양성 예와 피 열은 있으나 청각증상을 일으킬 정도로 크지 않은 무증상 또는 잠복기의 상반고리관 피열이 혼재되어 있을 것이다. 실 제 상반고리관 피열증후군은 해부학 연구에서 보인 $1.3 \%$ 보 다도 훨씬 드물게 발견된다는 점과 실제로 상반고리관 피열 증후군 환자에서 피열 부위의 크기가 클수록 증상이 심해진 다는 연구 결과는 상반고리관 피열의 크기가 작으면 증상이 없을 수도 있음을 암시한다. ${ }^{10}$

본 연구에 있어 관상면 영상에서 상반고리관 피열이 확인된 $64 ㄱ ㅟ(14.7 \%)$ 는 $0.625 \mathrm{~mm}$ 간격의 관상면 영상에서 한 슬라 이스 이상의 피열이 확인되는 경우를 모두 포함한 것이고 두 슬라이스 이상을 기준으로 하면 48귀(11.1\%), 세 슬라이스 이상을 기준으로 하면 31귀(7.1\%)로 점점 줄어들어 위양성률 을 낮출 수 있다. 그러나 $\mathrm{TBCT}$ 마다 관상면 영상에서 상반고 리관이 출현하는 슬라이스의 수가 5 개에서 9 개로 넓은 편차 를 보이므로 단순히 피열이 확인되는 슬라이스 수를 기준으 로 삼기보다는 [피열 확인 슬라이스/상반고리관 확인 슬라이
스] 비율을 진단 기준으로 삼는 것이 타당할 것으로 보고 피 열이 확인되는 64 귀에 대하여 그 비율을 구하였다. 관상면 영상에서 상반고리관이 출현하는 슬라이스의 수에 편차가 큰 것은 전술한 바와 같이 상반고리관의 축과 관상면에 45 도 의 각도 차이가 있고 상반고리관 골미로의 두께가 매우 얇기 때문으로 생각된다. 본 연구에서는 $\mathrm{TBCT}$ 관상면 영상에서 보이는 [피열 확인 슬라이스/상반고리관 확인 슬라이스] 비율 로 상반고리관 피열증후군을 진단할 때 가장 적절한 절단값 은 0.67 로 나타났고, 절단값을 초과하는 비율을 보인 귀는 총 434 귀 중 9귀 $(9 / 434,2.1 \%)$ 로 기존에 보고된 해부학적 연구의 유병률 $1.3 \%^{8}$ 에 다소 근접하게 나타났다. 절단값 이상의 9 귀 중 3귀는 상반고리관 피열증후군으로 확진되었고 나머지 6 귀 는 피열이 실제로 존재하나 그 크기가 청각증상을 일으킬 정 도로 크지 않은 무증상 또는 잠복기의 상반고리관 피열로 추 정된다.

상반고리관 피열증후군과 관련된 증상이 있어서 $\mathrm{TBCT}$ 가 촬영된 12 귀 중 관상면 영상과 상반고리관 재구성 영상의 결 과가 일치하지 않는 예는 없었다. 따라서 상반고리관 재구성 영상이 만족하게 얻어지지 못하였을 경우에도 관상면 영상 에서 [피열 확인 슬라이스/상반고리관 확인 슬라이스] 비율 이 0.67보다 크고 특징적인 증상이나 이학적 검사 소견이 수 반되는 경우 상반고리관 피열증후군을 확진하는 데 무리가 없을 것으로 판단된다.

$\mathrm{Minor}^{4}$ 는 상반고리관 결손증후군 환자에서 큰 소리와 압 력에 의해 어지럼증이 유발되는 Tullio 현상과 Hennebert 징 후가 각각 환자의 $90 \%$ 와 $73 \%$ 에서 호소하는 가장 흔한 증상 으로 보고하였고 자가강청, 청각과민 등이 그 뒤를 잇고 있 다. Beyea 등믄 16 예의 상반고리관 피열증후군 중 8예에서 박동성 이명을 보고한 바 있다. 본 연구에서도 Tullio 현상과 자가강청 및 청각과민은 가장 민감도와 양성 예측도가 높은 증상으로 나타났으며 세 가지 증상을 모두 가지고 있는 환자 에서 민감도 및 특이도 $100 \%$ 확률을 보여 세 가지 증상을 모 두 가지는 경우 상반고리관 피열증후군을 강력히 의심할 수 있을 것으로 보인다.

본 연구에서 성별과 나이는 $\mathrm{TBCT}$ 로 진단되는 상반고리관 피열과 무관한 것으로 나타났다. 기존 연구에 따르면 상반고 리관을 덮는 뼈 두께는 나이가 많은 환자에서 감소한다고 보 고되고 있으므로하나이와 상관관계가 예상되었으나 본 연구 에서는 특별한 상관관계가 없는 것으로 나타났다.

본 연구의 한계점은 정상인을 대상으로 $\mathrm{TBCT}$ 를 얻은 것 이 아니고 이과적 증상으로 이비인후과에 방문한 환자들의 영상을 분석하였으므로 일반적인 무증상 상반고리관 피열 또는 상반고리관 피열증후군의 위양성률을 구하지는 못하였 
다. 또 연구의 대상 중 실제 상반고리관 증후군으로 확진된 환자는 3명으로 그 수가 적기 때문에 향후 상당 기간 동안 전 향적 연구를 통하여 관상면 영상의 [피열 확인 슬라이스/상 반고리관 확인 슬라이스] 비율과 증상을 조합하여 상반고리 관 피열증후군을 확진할 수 있는 지표를 개선시켜야 할 필요 가 있다.

$\mathrm{TBCT}$ 관상면 영상에서 상반고리관 피열을 확인할 수 있 는 경우라도 실제로 환자가 동반 증상이 있어서 상반고리관 피열증후군으로 확진되는 예는 일부분이다. 대다수는 무증 상 증례이거나 위양성으로 진단된 증례였다. 상반고리관 피 열증후군의 전형적인 증상과 $\mathrm{TBCT}$ 관상면에서 [피열 확인 슬라이스/상반고리관 확인 슬라이스] 비율을 조합하여 적용 할 경우 상반고리관 재구성 영상 없이도 상당히 높은 민감도 와 특이도를 보이는 정확한 진단방법이 될 것으로 사료된다.

\section{REFERENCES}

1) Smullen JL, Andrist EC, Gianoli GJ. Superior semicircular canal dehiscence: a new cause of vertigo. J La State Med Soc 1999;151(8): 397-400.

2) Minor LB, Solomon D, Zinreich JS, Zee DS. Sound- and/or pressureinduced vertigo due to bone dehiscence of the superior semicircular canal. Arch Otolaryngol Head Neck Surg 1998;124(3):249-58.
3) Song JJ, Kim JS, Kim JH, Koo JW. A case of superior semicircular canal dehiscence syndrome. Korean J Otolaryngol-Head Neck Surg 2007;50(5):451-5.

4) Minor LB. Clinical manifestations of superior semicircular canal dehiscence. Laryngoscope 2005;115(10):1717-27.

5) Belden CJ, Weg N, Minor LB, Zinreich SJ. CT evaluation of bone dehiscence of the superior semicircular canal as a cause of soundand/or pressure-induced vertigo. Radiology 2003;226(2):337-43.

6) Williamson RA, Vrabec JT, Coker NJ, Sandlin M. Coronal computed tomography prevalence of superior semicircular canal dehiscence. Otolaryngol Head Neck Surg 2003;129(5):481-9.

7) Cho YW, Shim BS, Kim JW, Kim TS, Ahn JH, Chung JW, et al. Prevalence of radiologic superior canal dehiscence in normal ears and ears with chronic otitis media. Laryngoscope 2014;124(3):746-50.

8) Carey JP, Minor LB, Nager GT. Dehiscence or thinning of bone overlying the superior semicircular canal in a temporal bone survey. Arch Otolaryngol Head Neck Surg 2000;126(2):137-47.

9) Davey S, Kelly-Morland C, Phillips JS, Nunney I, Pawaroo D. Assessment of superior semicircular canal thickness with advancing age. Laryngoscope 2015;125(8):1940-5.

10) Pfammatter A, Darrouzet V, Gärtner M, Somers T, Van Dinther J, Trabalzini F, et al. A superior semicircular canal dehiscence syndrome multicenter study: is there an association between size and symptoms? Otol Neurotol 2010;31(3):447-54.

11) Beyea JA, Agrawal SK, Parnes LS. Transmastoid semicircular canal occlusion: a safe and highly effective treatment for benign paroxysmal positional vertigo and superior canal dehiscence. Laryngoscope 2012; 122(8):1862-6. 